Teknik, 36 (2), 2015, 75-80

\title{
KINETIKA REAKSI ESTERIFIKASI GLISEROL DAN ASAM ASETAT MENJADI TRIACETIN MENGGUNAKAN KATALIS ASAM SULFAT
}

\author{
Hantoro Satriadi ${ }^{*}$ \\ Jurusan Teknik Kimia, Fakultas Teknik, Universitas Diponegoro, \\ Jl. Prof. Soedarto, SH, Kampus Undip Tembalang, Semarang, Indonesia 50275
}

\begin{abstract}
Abstrak
Biodiesel merupakan salah satu energi alternatif yang diharapkan dapat menggantikan bahan bakar diesel. Gliserol merupakan produk dengan produksi biodiesel dari reaksi transesterifikasi. Gliserol saat diesterifikasi dengan asam asetat untuk membentuk triacetin. Kegunaan triacetin sangat baik untuk makanan dan non makanan. Untuk bahan makanan, triacetin dapat digunakan sebagai bahan aroma dalam permen, minuman dari susu, minuman ringan dan permen karet. Adapun non-makanan dapat digunakan untuk pelarut pada parfum, tinta cetak, pelarut dalam rasa, plasticizer untuk resin selulosa, polimer dan co-polimer, bahkan dapat digunakan sebagai bahan aditif bahan bakar untuk mengurangi knocking di mesin mobil. Dalam penelitian ini akan diperoleh kondisi optimum pembuatan triacetin. Volume total gliserol dan asam asetat $600 \mathrm{ml}$, kecepatan pengadukan $100 \mathrm{rpm}$ dan berat katalis adalah 5\% berat gliserol. Dalam penelitian ini proses analisis kualitatif dengan menggunakan instrumen FTIR telah mendeteksi adanya produk triacetin. Hasil analisis kuantitatif diperoleh persamaan kecepatan reaksi esterifikasi dan kondisi optimum yang dihasilkan pada rasio mol reagen gliserol dan asam asetat 1:7 dengan temperatur $120{ }^{\circ} \mathrm{C}$ pada menit ke-5 dengan nilai konversi sebesar $67,63 \%$.
\end{abstract}

Kata kunci : gliserol; asam asetat; esterifikasi; triacetin; konversi

\begin{abstract}
[Title: Kinetics of Esterification Reaction of Triacetin Formation from Glycerol and Acetic Acid Using Sulfuric Acid Catalyst] Biodiesel, as one of alternative energy, is expected to replace diesel fuel. Glycerol is a by product of biodiesel production from transesterification reaction. The glycerol was esterified with acetic acid to form triacetin. The triacetin was useful for food and non-food application. For food application, the triacetin can be used as a fragrance ingredient in candy, beverages from milk, soft drinks and chewing gum. Meanwhile, for non-food materials, it can be used for solvent triacetin on perfumes, printing ink, solvent in flavor, plasticizer for cellulose resin, polymer and co-polymers, it can even be used as fuel additives to reduce knocking in car engines. In this study, the research results in optimum conditions on manufacturing triacetin. Total volume of glycerol and acetic acid is $600 \mathrm{ml}$, stirring speed is $100 \mathrm{rpm}$ and the catalyst laoding is $5 \mathrm{wt} \%$ glycerol. From qualitative analysis using FTIR, the triacetin product was detected. From quantitative analysis, the rate equation of esterification reaction and optimum conditions were resulted at mole ratio of glycerol and acetic acid of reagents $1: 7$, temperature of $120^{\circ} \mathrm{C}$ at 5 minutes process and the conversion of $67.63 \%$.
\end{abstract}

Keywords : glycerol; acetic acid; esterification; triacetin; conversion

\section{Pendahuluan}

Biodiesel adalah bahan bakar yang terdiri dari campuran mono-alkyl ester dari rantai panjang asam lemak, dan terbuat dari sumber yang terbaharui seperti minyak nabati atau lemak hewan. Reaksi

\footnotetext{
${ }^{*}$ Penulis Korespondensi.

E-mail: hantorosatriadi@yahoo.com
}

transesterifikasi trigliserida dalam minyak nabati atau lemak hewani dengan alkohol (methanol/etanol) yang menghasilkan metil ester asam lemak (Fatty Acids Methyl Esters/ FAME) atau biodiesel dan gliserol (gliserin) sebagai produk samping.

Gliserol adalah produk samping produksi biodisel dari reaksi transesterifikasi. Gliserol (1,2,3 propanetriol) merupakan sesuatu yang tidak berwarna, tidak berbau dan merupakan cairan kental 


\section{Teknik, 36 (2), 2015, 76}

yang memiliki rasa manis (Pagliaro dan Rossi, 2008). Gliserol bila diesterifikasi dengan asam asetat akan membentuk triacetin. Kegunaan triacetin sangat banyak baik untuk keperluan bahan makanan maupun non makanan. Untuk bahan makanan, triacetin dapat digunakan sebagai bahan aroma pada permen (gulagula), minuman dari susu, minuman ringan dan permen karet. Sedangkan untuk bahan non makanan triacetin dapat digunakan untuk pelarut pada parfum, tinta cetak, pelarut pada aroma, plastisizer untuk resin selulosa, polimer dan ko-polimer, bahkan dapat digunakan sebagai bahan aditif bahan bakar untuk mengurangi knocking pada mesin mobil (Nuryoto dkk., 2010).

Triacetin dapat diproduksi dari reaksi gliserol dan asam asetat menggunakan katalisator. Pembuatan triacetin dengan mereaksikan gliserol dan asam asetat telah dilakukan oleh peneliti sebelumnya. Leonardo dkk. (2010) mempelajari reaksi gliserol dengan asam asetat pada suhu $120^{\circ} \mathrm{C}$ selama 120 menit dengan memvariasikan katalis, perbandingan molar asam asetat dan gliserol 4:1 dengan berat katalis $2 \mathrm{mmol}$ berat asam asetat menggunakan katalis berupa zeolit beta, diperoleh konversi sebesar 94\% dengan selektivitas 4\%, dengan katalis berupa K-10 diperoleh konversi sebesar $100 \%$ dengan selektivitas $6 \%$, dengan katalis berupa niobium phosphate diperoleh konversi sebesar $100 \%$ dengan selektivitas 7\%, dengan katalis berupa amberlyst-15 diperoleh konversi sebesar $100 \%$ dengan selektivitas 24\%. Balaraju dkk. (2010) telah melakukan esterifikasi gliserol dan asam asetat menggunakan katalis tungstophosphoric acid (TPA) dan niobic acid $\left(\mathrm{Nb}_{2} \mathrm{O}_{5}\right)$, konversi tertinggi diperoleh pada katalis $25 \% \mathrm{TPA} / \mathrm{Nb}_{2} \mathrm{O}_{5}$ dengan berat $200 \mathrm{mg}$, temperatur $120^{\circ} \mathrm{C}$ selama 4 jam dengan perbandingan mol gliserol dan asam asetat 1:5 diperoleh konversi sebesar 98\% dengan selektivitas 98\%. Xiaoyuan dkk., (2010) mereaksikan gliserol dan asam asetat dengan perbandingan mol 1:6 selama 4 jam pada temperatur $115^{\circ} \mathrm{C}$ menggunakan katalis amberlyst-35 sebesar 0,5 gram diperoleh konversi sebesar $100 \%$ dengan selektivitas 25\%. Padigapati dkk. (2010) telah melakukan esterifikasi antara gliserol dan asam asetat dengan perbandingan molar pereaksi 1:6 selama 3 jam pada temperatur $393 \mathrm{~K}$ serta memvariasikan katalis dengan jumlah $5 \%$ berat gliserol diperoleh konversi pada katalis $\mathrm{ZrO}_{2}$ sebesar $86 \%, \mathrm{TiO}_{2}-\mathrm{ZrO}_{2}$ sebesar 93\%, $\quad \mathrm{WOx} / \mathrm{TiO}_{2}-\mathrm{ZrO}_{2}$ sebesar $100 \%$ dan $\mathrm{MoOx} / \mathrm{TiO}_{2}-\mathrm{ZrO}_{2}$ sebesar $100 \%$. Ferreira dkk. (2009) mereaksikan 2 gram gliserol dengan $20 \mathrm{ml}$ asam asetat menggunakan katalis 0,2 gram dodecamolybdophosphoric-NaUSY selama 3 jam pada temperatur $120^{\circ} \mathrm{C}$ diperoleh konversi sebesar $68 \%$ dengan selektivitas 2\%. Ferreira dkk. (2011) mereaksikan gliserol dengan asam asetat dengan perbandingan molar 1:16 selama 3 jam pada temperatur $120^{\circ} \mathrm{C}$ menggunakan katalis 0,2 gram dodecatungstophosphoric acid diperoleh konversi sebesar $86 \%$ dengan selektivitas $11 \%$. Jagadeeswaraiah dkk. (2010) telah mereaksikan gliserol dengan asam asetat dengan perbandingan molar 1:5 selama 4 jam pada temperatur $120^{\circ} \mathrm{C}$ berat katalis 0,2 gram TPA/ $\mathrm{Cs}_{2}-\mathrm{ZrO}_{2}$ diperoleh konversi sebesar 93\% selektivitas $17 \%$.

Katalis yang digunakan oleh peneliti-peneliti sebelumnya belum pernah ada yang menggunakan katalis asam sulfat. Sedangkan asam sulfat bersifat sebagai katalis juga dapat menyerap air sehingga dapat digunakan sebagai katalis untuk produksi triacetin. Dengan kelebihan sifat higroskopis, diharapkan air yang dilepaskan dapat diserap sehingga reaksi dapat berjalan ke arah produk, dengan demikian konversi akan meningkat.

Tujuan penelitian ini adalah untuk mempelajari kinetika laju reaksi esterifikasi glicerol dan asam asetat sehingga diperoleh persamaan laju reaksinya dan kondisi optimum reaksinya.

\section{Bahan dan Metode Penelitian \\ 2.1 Bahan}

Bahan yang digunakan adalah gliserol, asam asetat, asam sulfat, $\mathrm{NaOH}$ dan aquadest. Sebagai pendekatan dipakai gliserol technical grade dengan kemurnian $90 \%$ dan densitas sebesar $1,25 \mathrm{gr} / \mathrm{ml}$. Asam asetat dan asam sulfat yang digunakan adalah pro analyst dengan kemurnian $99 \%$ dari Merck. $\mathrm{NaOH}$ yang digunakan adalah pro analyst dengan kadar $99 \%$ dari Merck.

\subsection{Metode Penelitian}

Penelitian dilakukan dengan cara memanaskan gliserol dan asam asetat ditempat yang terpisah. Setelah mencapai temperatur yang diinginkan kemudian memasukkannya ke dalam labu leher tiga beserta asam sulfat, dan mengatur temperatur sesuai dengan yang diinginkan. Setelah menit ke-5 mengambil sampel kemudian memasukkanya ke dalam lemari pendingin, demikian seterusnya hingga menit ke-60. Proses analisa dengan cara analisa kualitatif dan kuantitatif. Analisa kualitatif menggunakan alat FTIR untuk membuktikan adanya triacetin. Sedangkan analisa kuantitatif menggunakan metode titrasi acidi alkali dengan $\mathrm{NaOH}$ 0,5 $\mathrm{N}$ sebagai penitran untuk mencari nilai konversi gliserol.

\section{Hasil dan Pembahasan}

\subsection{Analisa Kualitatif dengan Spektrofotometer} Fourier Transform Infra Red (FTIR)

Analisa ini dimaksudkan untuk mengetahui ada tidaknya kandungan triacetin yang terdapat di dalam sampel. Hasil analisa FTIR sampel produk dapat dilihat pada Gambar 1 dan 2 . 


\section{Teknik, 36 (2), 2015, 77}

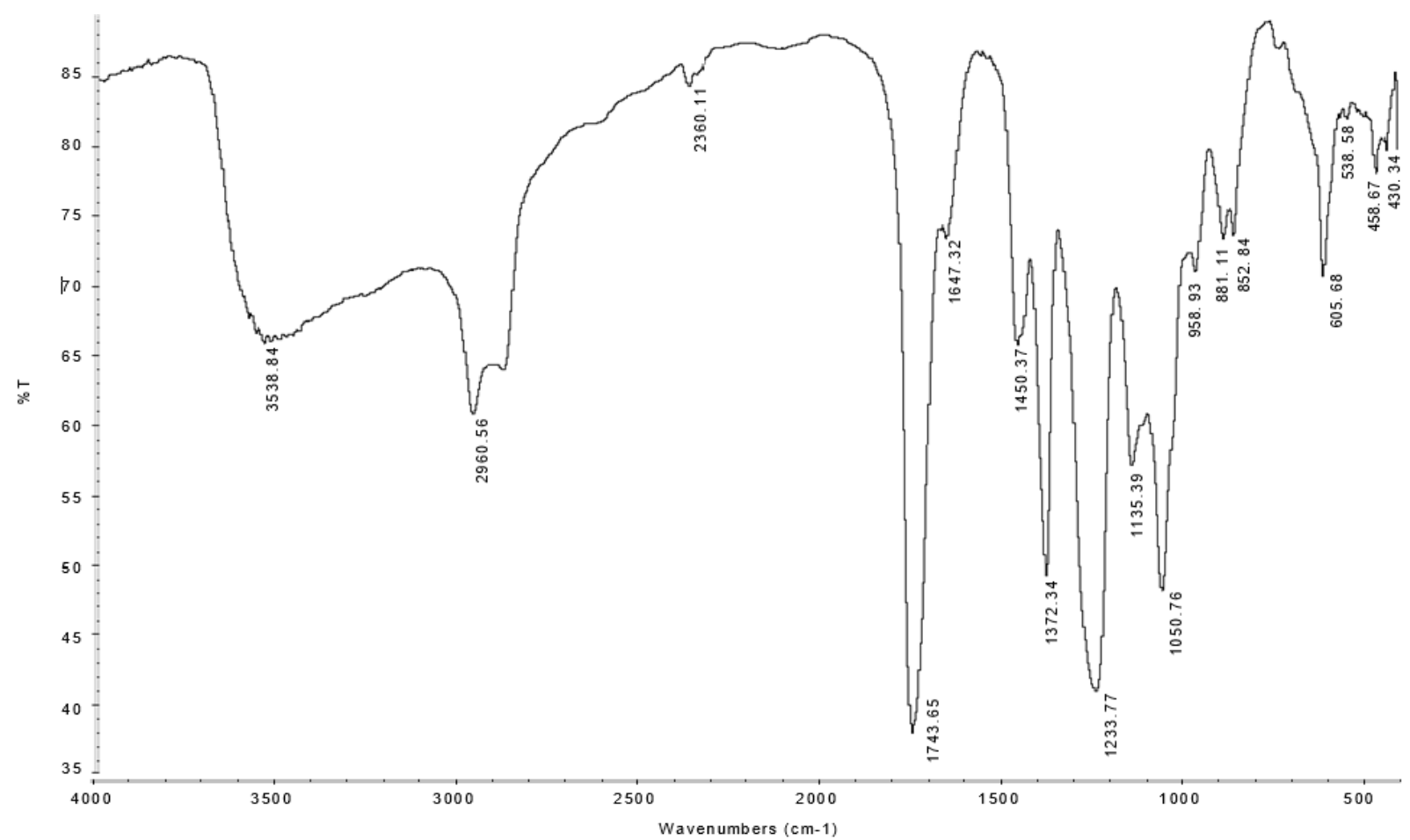

Gambar 1. Spektra IR sampel produk yang mengandung triacetin

Dari Gambar 1 dapat diperoleh grup gugus fungsi dari beberapa senyawa diantaranya adalah seperti terlihat pada Tabel 1 .

Tabel 1. Panjang Gelombang Hasil Spektra IR Sampel (Vogel, 1989)

\begin{tabular}{cc}
\hline Wavenumber $\left(\mathrm{cm}^{-1}\right)$ & Group \\
\hline 538,58 & $\mathrm{C}-\mathrm{Br}$ \\
605,68 & $\mathrm{C}-\mathrm{Cl}$ \\
852,84 & $\mathrm{C}-\mathrm{C}$ \\
881,1 & $\mathrm{C}-\mathrm{C}$ \\
958,93 & $\mathrm{C}-\mathrm{C}$ \\
1050,76 & $\mathrm{C}-\mathrm{F}$ \\
1135,39 & $\mathrm{C}-\mathrm{F}$ \\
1233,77 & $\mathrm{C}-\mathrm{F}$ \\
1372,34 & $\mathrm{CH}_{3-}^{-},-\mathrm{CH}_{2-}$ \\
1450,37 & $\mathrm{CH}_{3-}^{-},-\mathrm{CH}_{2-}^{-}$ \\
1647,32 & $\mathrm{C}=\mathrm{C}$ \\
1743,65 & $\mathrm{C}=\mathrm{O}(\mathrm{ester})$ \\
2960,56 & $\mathrm{C}-\mathrm{H}$ (aliphatic) \\
3538,58 & $\mathrm{C}-\mathrm{Br}$ \\
\hline
\end{tabular}

\footnotetext{
Triacetin memiliki gugus fungsi $\mathrm{CH}_{3} \mathrm{COOCH}_{2} \mathrm{CH}\left(\mathrm{CH}_{3} \mathrm{COO}\right) \mathrm{CH}_{2}\left(\mathrm{CH}_{3} \mathrm{COO}\right)$ yang tergolong dalam grup ester dengan panjang gelombang 1700-1750 $\mathrm{cm}^{-1}$ (Vogel, 1989). Dari Tabel 1 dapat dilihat bahwa hasil Spektra IR Sampel terdapat panjang gelombang $1743,65 \mathrm{~cm}^{-1}$ yang tergolong dalam grup ester. Hal ini membuktikan bahwa di dalam sampel terdapat triacetin.
}

Dari Gambar 2 dapat dilihat bahwa dari kemiripan library beberapa senyawa diperoleh bahwa Spektra IR Sampel memiliki kemiripan tertinggi dengan triacetin sebesar $81 \%$. Hal ini membuktikan bahwa di dalam sampel terdapat triacetin.

\subsection{Analisa Kuantitatif}

Dari hasil penelitian pada perbandingan mol pereaksi gliserol dengan asam asetat 1:3 dengan temperatur $80,90,100,110$ dan $120^{\circ} \mathrm{C}$ dihasilkan nilai konversi seperti terlihat pada Gambar 3. Dari Gambar 3 dapat diketahui bahwa nilai konversi pada temperatur $80^{\circ} \mathrm{C}$ hingga temperatur $120^{\circ} \mathrm{C}$ mengalami kenaikkan. Hal ini terjadi karena dengan semakin tinggi temperatur reaksi, kecepatan reaksi juga semakin meningkat. Hal ini sesuai dengan persamaan Arrhenius sebagaimana di Persamaan (1).

$$
\mathrm{k}=\mathrm{A} \cdot \mathrm{e}^{-\mathrm{E} /}
$$

Jika nilai temperatur reaksi semakin tinggi, maka kecepatan reaksi akan bertambah besar sehingga konversi yang diperoleh semakin besar pula. Dari Gambar 3 dapat juga diketahui bahwa nilai konversi pada menit ke-0 hingga menit ke-60 mengalami kenaikkan. Hal ini terjadi karena semakin lama waktu reaksi maka konversi semakin besar akibat kesempatan pereaksi untuk saling bertumbukan semakin besar (Levenspiel, 1999).

Dari hasil penelitian pada temperatur $120^{\circ} \mathrm{C}$ dengan perbandingan mol pereaksi gliserol dengan asam asetat $1: 3 ; 1: 4 ; 1: 5 ; 1: 6$; dan $1: 7$ dihasilkan nilai konversi seperti terlihat pada Gambar 4. 
Teknik, 36 (2), 2015, 78

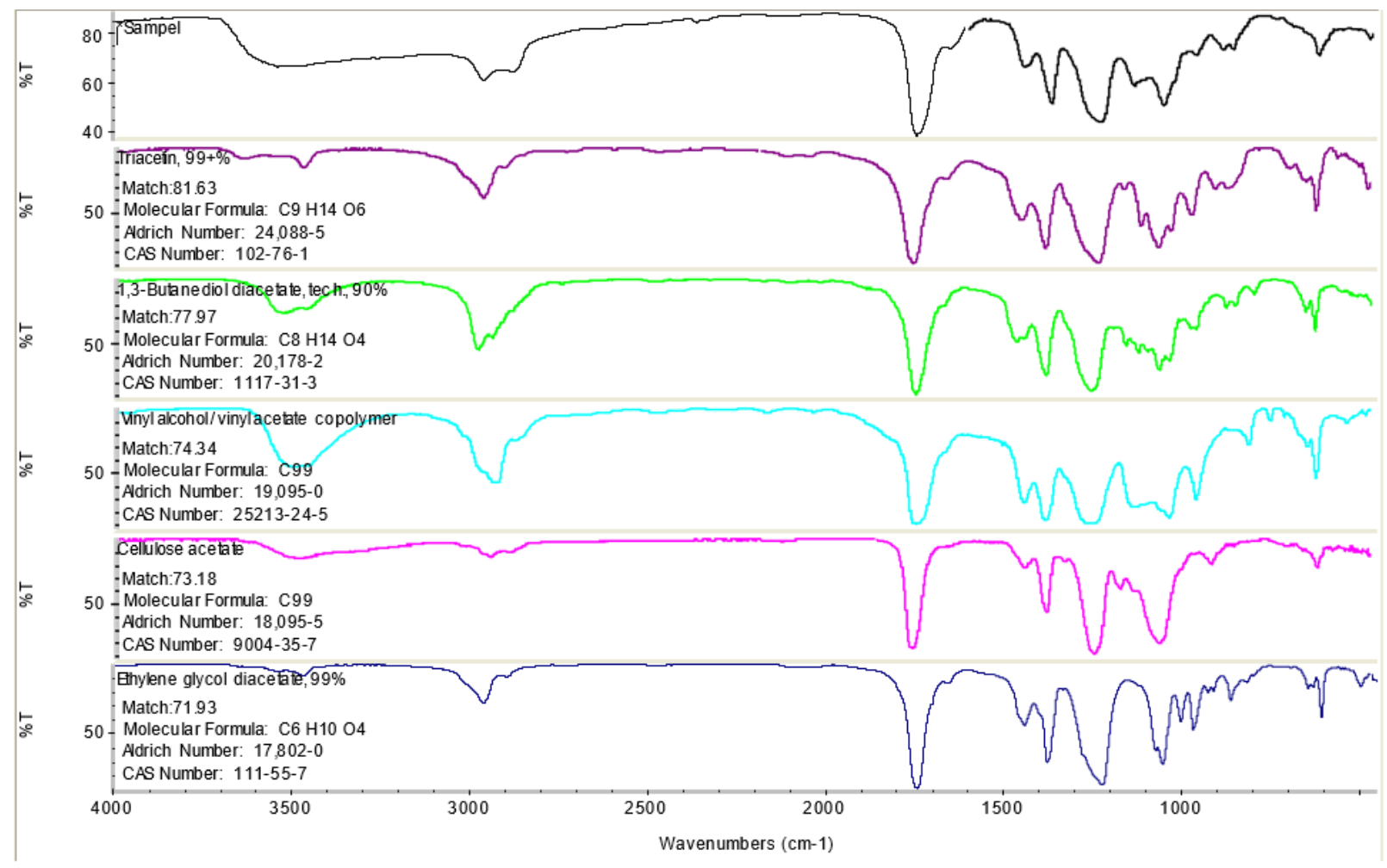

Gambar 2. Kemiripan spektra sampel dengan library

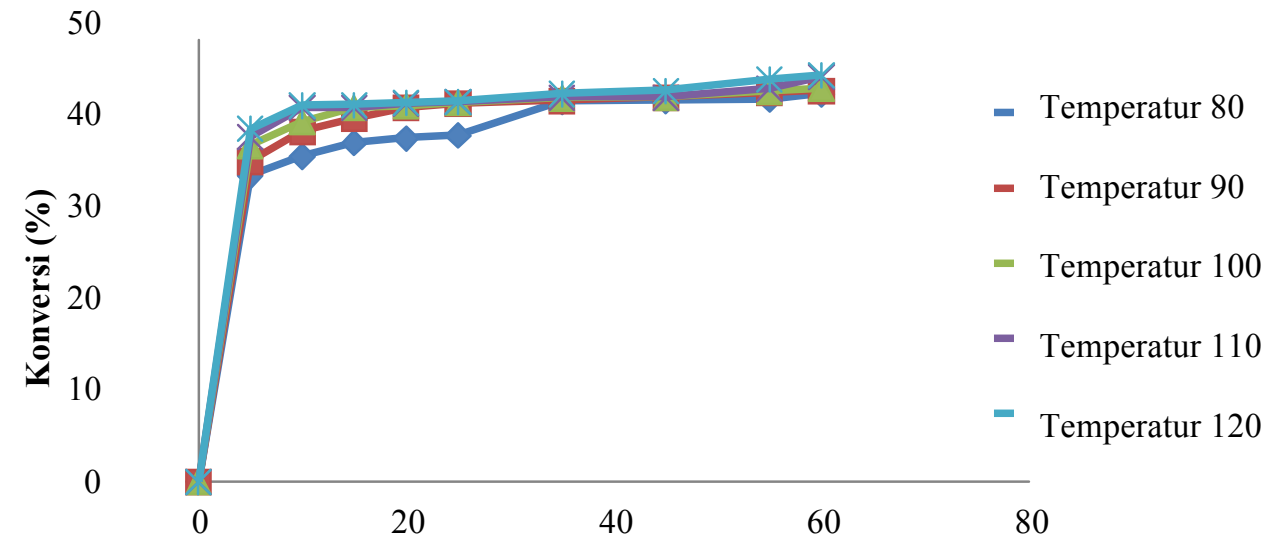

Waktu Reaksi (menit)

Gambar 3. Grafik hubungan antara temperatur reaksi dan konversi pada perbandingan mol pereaksi 1:3

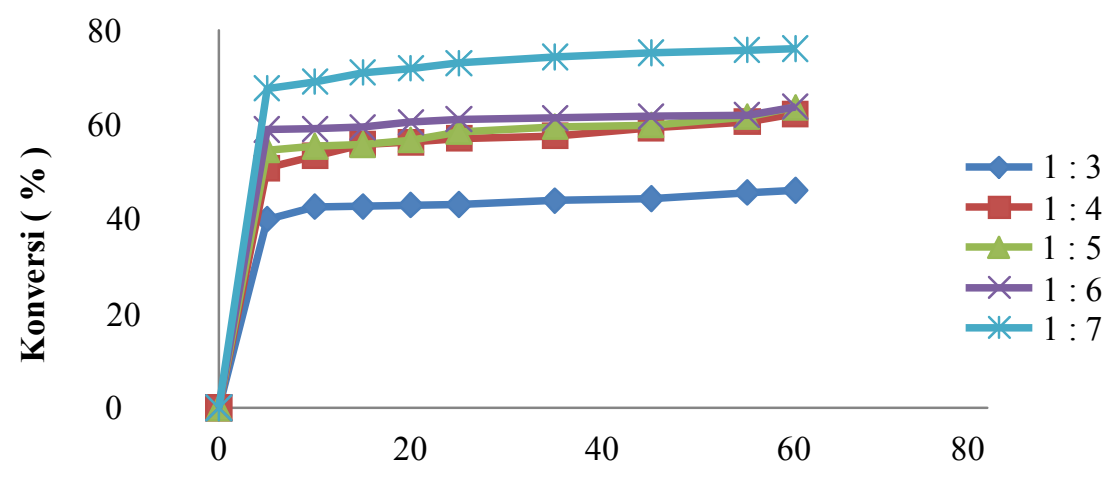

Waktu Reaksi ( menit )

Gambar 4. Grafik hubungan antara perbandingan mol pereaksi dan konversi 


\section{Teknik, 36 (2), 2015, 79}

Dari Gambar 4 dapat diketahui bahwa nilai konversi pada per bandingan mol gliserol dan asam asetat 1:3 hingga 1:7 mengalami kenaikkan. Hal ini disebabkan karena esterifikasi merupakan reaksi dapat balik, sehingga jika salah satu reaktan dibuat berlebih, maka reaksi akan bergeser ke arah kanan dan bertumbuknya antar molekul semakin besar yang mengakibatkan konversi semakin besar pula (McKetta, 1977). Dari Gambar 4 dapat juga diketahui bahwa kondisi optimum dihasilkan pada perbandingan mol pereaksi gliserol terhadap asam asetat 1:7 temperatur $120^{\circ} \mathrm{C}$ menit ke-5 dengan nilai konversi sebesar $67,63 \%$.

Dari hasil penelitian yang telah dilakukan diperoleh konversi yang tinggi. Hal ini dapat dibandingkan dengan hasil penelitian terdahulu seperti yang terlihat pada Tabel 2.

Tabel 2. Perbandingan Hasil penelitian pembuatan triacetin

\begin{tabular}{lcc}
\hline \multicolumn{1}{c}{ Peneliti } & Konversi & Selektifitas \\
\hline Leonardo dkk. (2010) & $100 \%$ & $24 \%$ \\
Balaraju dkk. (2010) & $98 \%$ & $98 \%$ \\
Xiaoyuan dkk. (2010) & $100 \%$ & $25 \%$ \\
Padigapati dkk. (2010) & $100 \%$ & - \\
Ferreira dkk. (2009) & $68 \%$ & $2 \%$ \\
Ferreira dkk. (2011) & $86 \%$ & $11 \%$ \\
Jagadeeswaraiah dkk. & $93 \%$ & $17 \%$ \\
$(2010)$ & & \\
\hline
\end{tabular}

Sementara itu dari hasil penelitian pada perbandingan mol pereaksi gliserol dengan asam asetat $1: 3$ dengan temperatur $80,90,100$, dan $120^{\circ} \mathrm{C}$ dihasilkan nilai laju reaksi seperti terlihat pada Gambar 5.

Gambar 5 menunjukkan hubungan antara temperatur dengan $\mathrm{k}_{\mathrm{f}}$. Dari persamaan $\ln \mathrm{k}_{\mathrm{f}}^{\prime}=$ $2,965 x+0,012$ diperoleh energi aktivasi 24,651 $\mathrm{kj} / \mathrm{mol}$ dan harga $\mathrm{A}=1,012$ detik $^{-1}$, sehingga didapat $\mathrm{k}$ $=1,012 \cdot \mathrm{e}^{2,965 / \mathrm{T}}$.
Pada hasil penelitian dengan temperatur $120^{\circ} \mathrm{C}$ dengan perbandingan mol pereaksi gliserol dengan asam asetat 1:3, 1:4, 1:5, 1:6, dan 1:7 dihasilkan nilai laju reaksi seperti terlihat pada Tabel 3 .

Tabel 3. Perbandingan Mol Pereaksi dengan Laju Reaksi

\begin{tabular}{cc}
\hline $\begin{array}{c}\text { Perbandingan mol } \\
\text { gliserol dan asam asetat }\end{array}$ & $\mathbf{k}\left(\right.$ detik $\left.^{\mathbf{- 1}}\right)$ \\
\hline $1: 3$ & 1,003973 \\
$1: 4$ & 1,007366 \\
$1: 5$ & 1,008072 \\
$1: 6$ & 1,008717 \\
$1: 7$ & 1,014707 \\
\hline
\end{tabular}

Dari Tabel 3 dapat diketahui bahwa nilai laju reaksi pada perbandingan mol gliserol dan asam asetat 1:3 hingga 1:7 mengalami kenaikan. Hal ini disebabkan konsentrasi reaktan semakin besar dimana zat yang konsentrasinya besar mengandung jumlah partikel yang lebih banyak, sehingga partikelpartikelnya tersusun lebih rapat dibanding zat yang konsentrasinya rendah. Partikel yang susunannya lebih rapat akan lebih sering bertumbukan sehingga kemungkinan terjadinya reaksi semakin besar.

\section{Kesimpulan}

Dari penelitian yang telah dilakukan, didapat Persamaan laju reaksi, $-\frac{d C_{A}}{d t}=\ln \frac{X_{A e}-\left(2 X_{A e}-1\right) X_{A}}{X_{A e}-X_{A}}=$ $2 k 1\left(\frac{1}{X_{A e}}-1\right) C_{A o} . t$, dengan harga $\mathrm{k}=1,012 \cdot \mathrm{e}^{2,965 / \mathrm{T}}$ dan $\mathrm{R}^{2}=0,880$. Kondisi optimum diperoleh dengan mereaksikan gliserol dan asam asetat menggunakan katalis asam sulfat $5 \%$ berat gliserol selama 1 jam diperoleh kondisi optimum pada perbandingan mol pereaksi gliserol dan asam asetat $1: 7$ temperatur $120^{\circ} \mathrm{C}$ menit ke-5 dengan nilai konversi sebesar $67,63 \%$.

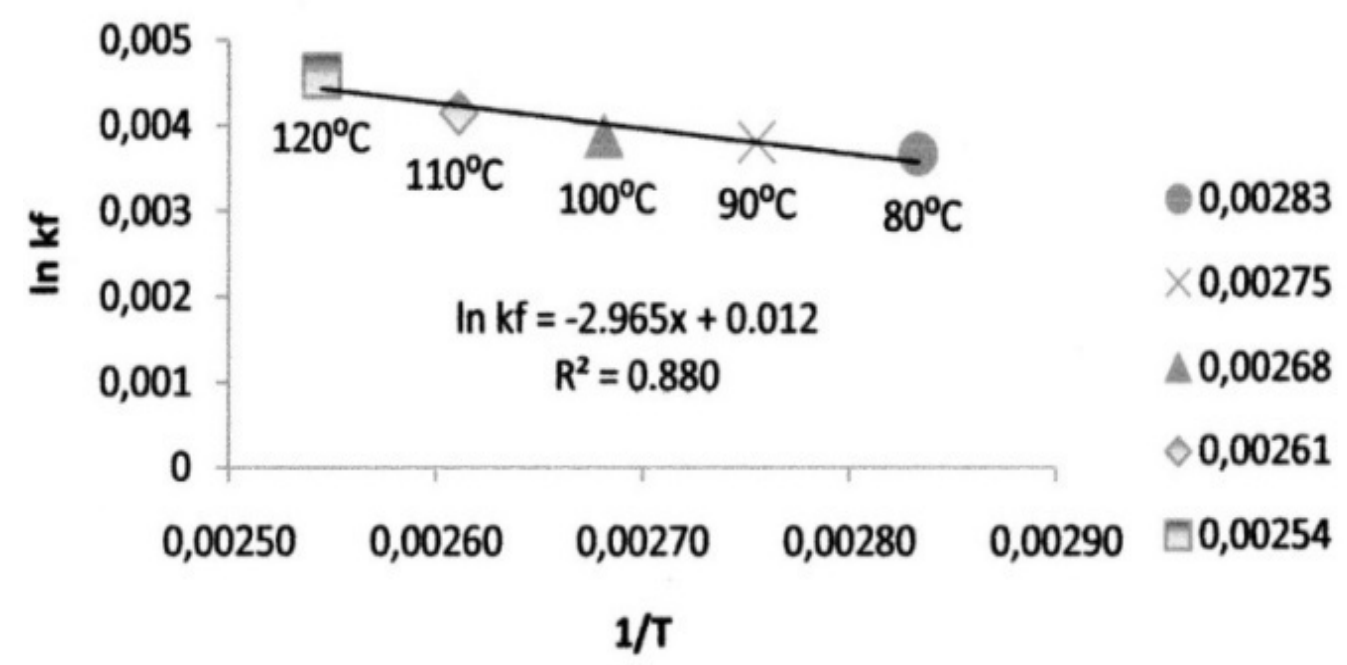

Gambar 5. Grafik hubungan antara $\ln \mathrm{k}$ dan $1 / \mathrm{T}$ pada perbandingan mol pereaksi 1:3 


\section{Teknik, 36 (2), 2015, 80}

\section{Daftar Pustaka}

Balaraju, M., Nikhitha, P., Jagadeeswaraiah, K., Srilatha, K., Sai Prasad, P. S., \& Lingaiah, N. (2010). Acetylation of glycerol to synthesize bioadditives over niobic acid supported tungstophosphoric acid catalysts. Fuel Processing Technology, 91 (2), 249-253.

Ferreira, P., Fonseca, I. M., Ramos, a. M., Vital, J., \& Castanheiro, J. E. (2009). Esterification of glycerol with acetic acid over dodecamolybdophosphoric acid encaged in USY zeolite. Catalysis Communications, 10 (5), 481-484.

Ferreira, P., Fonseca, I. M., Ramos, A. M., Vital, J., \& Castanheiro, J. E. (2011). Acetylation of glycerol over heteropolyacids supported on activated carbon. Catalyst Communications, 12 (7), 573-576.

Jagadeeswaraiah, K., Balaraju, M., Prasad, P. S. S., \& Lingaiah, N. (2010). Applied Catalysis A : General Selective esterification of glycerol to bioadditives over heteropoly tungstate supported on Cs-containing zirconia catalysts. Applied Catalysis A, General, 386 (1-2), 166170.

Liao, X., Zhu, Y., Wang, S., Chen, H., \& Li, Y. (2010). Theoretical elucidation of acetylating glycerol with acetic acid and acetic anhydride, Applied Catalysis B : Environmental, 94, 6470.
Levenspiel, Octave., (1999). Chemical Reaction Engineering $3^{\text {th }}$ edition. Department of Chemical Engineering Oregon State University, New York.

McKetta, J. J, and Cunningham, W. A., (1977). Encyclopedia of Chemical Processing and Design vol 2. Marcel Dekker, Inc, New York.

Nuryoto, Sulistyo,H., Rahayu S.S., Sutijan. (2010). Uji Performa Katalisator Resin Penukar Ion Untuk Pengolahan Hasil Samping Pembuatan Biodiesel Menjadi Triacetin. Seminar Rekayasa Kimia Dan Proses 2010.

Pagliaro, Mario., Rossi, Michele., 2008. The Future of Glycerol: New Uses of a Versatile Raw Material. RSC Green Chemistry Book Series.

Reddy, Padigapati. S., Sudarsanam, P., Raju, G., \& Reddy, B. M. (2010). Synthesis of bioadditives: Acetylation of glycerol over zirconia-based solid acid catalysts. Catalyst Communications, 11 (15), 1224-1228.

Silva, L. N., Gonçalves, V. L. C., \& Mota, C. J. A. (2010). Catalytic acetylation of glycerol with acetic anhydride. Catalyst Communications, 11 (12), 1036-1039.

Vogel, A.I., (1989). Textbook of Quantitative Chemical Analysis $5^{\text {th }}$ edition. New York: Longman Scientific and Technical. 